\title{
Ensayo del terrorismo de Estado en Argentina: el Operativo Independencia (Tucumán, 1975-1977)
}

\section{Santiago Garaño}

Consejo Nacional de Investigaciones Científicas y Técnicas. Universidad Nacional de Lanús. Universidad Nacional de Tres de Febrero. Equipo de Antropología Política y Jurídica, Facultad de Filosofía y Letras, de la Universidad de Buenos Aires, Argentina.

Correo electrónico: sgarano@hotmail.com

Artículo recibido: 20 de agosto de 2019 Aprobación final: 24 de octubre de 2019

\section{Resumen}

Este artículo tiene como objetivo aportar a una línea de estudios sobre el surgimiento del terrorismo de Estado en la Argentina, a partir del abordaje del Operativo Independencia, una campaña militar desarrollada en Tucumán entre febrero de 1975 y diciembre de 1977, donde el Ejército argentino por primera vez de manera masiva ensayó la desaparición forzada de personas como tecnología de represión política (que luego del golpe de Estado del 24 de marzo de 1976 se extendió al resto del país). A partir del análisis de documentos castrenses, realizaré una reconstrucción pormenorizada del desarrollo militar del Operativo Independencia, su planificación por las autoridades militares, las principales fases, actores intervinientes, modalidades y dinámicas de represión política desplegadas, todos ellos temas aún no abordados en el campo de los estudios sobre represión y violencia política en la Argentina. La hipótesis central es que el ejercicio directo de la represión en el Operativo Independencia permitió al Ejército entrenar al personal militar en la "zona de operaciones" de Tucumán y acumular experiencia sobre estas modalidades. 


\title{
Essay on State Terrorism in Argentina: The Operation Independence (Tucumán, Argentina, 1975-1977)
}

\begin{abstract}
The general purpose of this paper is to contribute to the study on the emergence of State terrorism in Argentina, deployed centrally during the last military dictatorship that took place between March 24, 1976 and December 10, 1983. To do so, we will address a paradigmatic case: the Operation Independence (Operativo Independencia), a military campaign developed in Tucumán between February 1975 and December 1977, a province located in the northwest of the country, where one year before the start of the de facto government this type of repression was implemented for the first time. In this work, we will carry out a detailed reconstruction of the military development of the Operation Independence, giving an account of how it was planned by the military authorities, its main phases, intervening actors and the modalities and dynamics of the political repression deployed during the Independence Operation; all issues not yet developed in the field of studies on repression and political violence. Our hypothesis is that the direct use of repression in the Operation Independence allowed the Army, to train the troops in this repressive modality, thanks to a system of personnel rotation that involved the bulk of active military personnel.
\end{abstract}

Keywords: Human Rights, Argentina, State Terrorism, Operation Independence, Tucumán.

\section{Introducción ${ }^{1}$}

Este artículo se propone aportar al estudio sobre el surgimiento del terrorismo de Estado en la Argentina, una modalidad de represión basada en la desaparición forzada de personas y la implementación de un sistema nacional de centros clandestinos de detención y un régimen de terror, desplegada centralmente durante la última dictadura militar que se extendió entre el 24 de marzo de 1976 y el 10 de diciembre de 1983. Para ello, me centraré en un caso paradigmático, el Operativo Independencia, una campaña militar desarrollada en Tucumán en la que, desde febrero de 1975, un año antes del inicio del gobierno de facto, se implementó por primera vez dicha modalidad represiva. ${ }^{2}$

Distintos investigadores han destacado la relevancia que tuvo esta campaña militar. Pilar Calveiro (1998) anticipó la tesis de que este Operativo representó el inicio de una política institucional de desaparición forzada de personas que se extendería a todo el país luego del golpe de Estado de 1976. Describiendo sucintamente

1 Agradezco la generosidad de Ana Concha, Mariel Alonso, Antonius Robben, Diego Nemec, Daiana Fusca y Daniel Valladares, que colaboraron para el acceso a materiales fundamentales para la escritura del presente texto.

2 Ver: CONADEP (1985); Comisión Bicameral investigadora de las violaciones a los derechos humanos en la provincia de Tucumán (1991); Duhalde (1999); Crenzel (2010). 
las fases del Operativo, Antonius Robben (2008) consideró que, a partir de esta campaña militar, las Fuerzas Armadas (FF.AA.) argentinas se convencieron de que la única forma de detener a la guerrilla era mediante el ejercicio del terror estatal. Por su parte, Marina Franco (2012) sostuvo que en Tucumán por primera vez los elementos programáticos de la doctrina antisubversiva -acción represiva, cívica y psicológica- se aplicaron en conjunto. Por mi parte, planteé que en el "teatro de operaciones" del sur de Tucumán se hizo una puesta en escena de una guerra no convencional, que se reveló como la escenografía más propicia para ocultar que, tras las bambalinas, se estaba exterminando y desapareciendo a miles de tucumanos (Garaño, 2012).

Si bien coincido con los planteos anteriormente citados, el estado actual de conocimiento sobre este tema nos muestra que aún resta realizar el análisis pormenorizado de cómo fue planificada esa campaña militar, los principales actores intervinientes y las modalidades y dinámicas de la represión política allí desplegadas.Ése es el objetivo de este artículo. Sobre esta temática, existen trabajos que abordan aspectos parciales: elementos de la doctrina militar que sustentó el operativo (Jemio, 2013); la complicidad del empresariado con la represión (Basualdo, 2015); la reconfiguración del espacio como efecto de la violencia (Colombo, 2017) y la inauguración, en plena dictadura, de cuatro pueblos emplazados en el sur tucumano que llevaban nombre de militares "caídos" durante el Operativo, como parte de las tareas de acción psicológica del Ejército (Garaño, 2015; Nemec, 2018).

Para desarrollar este tema aún en ciernes en el campo de los estudios sobre represión y violencia política en nuestro país, realizaré una reconstrucción detallada del desarrollo militar del Operativo Independencia como campaña contrainsurgente, a través del examen de documentos militares. ${ }^{3}$ Primero, sistematicé las directivas militares y órdenes secretas que regularon esta campaña, obrantes en la "Causa 13", tal como se conoce al proceso judicial contra los comandantes de las tres Fuerzas Armadas que integraron las tres primeras Juntas Militares que gobernaron durante la última dictadura militar. En segundo lugar, tomaré un documento denominado "Evaluación del Operativo Independencia”, elaborado en 1978 por el Estado Mayor del Ejército argentino, donde se hace una larga reseña de esta acción militar. A continuación, analizaré las memorias de aquellos que comandaron dicha acción militar: el "diario de campaña” de Adel Vilas (1977), que detalla los planes tácticos (PT) durante su comandancia; ${ }^{4}$ el "diario de guerra” del coronel Eusebio González Breard (1999), quien fuera uno de los jefes de inteligencia de esta acción militar entre 1975 y 1976; y la larga entrevista que su hijo José Luis le hizo al segundo comandante del Operativo, Antonio Domingo Bussi desde la cárcel (Bussi, 2011). ${ }^{5}$

3 Sobre esta dimensión, se destacan los Informes elaborados por el Equipo de relevamiento y análisis documental de los archivos del Ejército argentino, dependiente del Ministerio de Defensa, que identifican los principales responsables del esquema represivo (ver, Almada, 2015).

4 Para un análisis del manuscrito de Vilas, véase: Crenzel (2010).

5 Además de la sólida investigación de Rosendo Fraga (1988) sobre el Ejército entre 1973 1976, también tomaré libros basados en relatos de varios oficiales y suboficiales destinados a dicho operativo, que cabalgan entre la investigación periodística y la propaganda (Círculo Militar, 1976; Simeoni, 1985; FAMUS, 1988; Burzaco 1994). Para complementar las fuentes anteriores, retomaré material periodístico de la 
Este trabajo se inscribe en una serie consolidada de estudios históricos sobre la doctrina militar desarrollada por las Fuerzas Armadas (FF.AA.) argentinas desde 1955 en adelante. Entendemos la doctrina militar como un conjunto de proposiciones teórico-prácticas, dentro del ordenamiento general de las leyes, que orientaron la acción bélica y guiaron el accionar del Ejército contra los opositores políticos (Périès, 2009: 221; Slatman, 2010: 442; Pontoriero, 2016). Esteban Pontoriero (2016) mostró cómo, desde el golpe de Estado de 1955, las FF.AA. argentinas crearon un cuerpo doctrinario contrainsurgente nuevo, basado en una teoría y una metodología pensada para la represión de un enemigo interno y la militarización de la seguridad interna, que se diferenció de la tradicional doctrina de Defensa Nacional del Ejército (basada en la hipótesis tradicional de una guerra entre Argentina y sus países vecinos). Sumando una perspectiva regional, Pablo Scatizza argumentó que en las distintas dictaduras latinoamericanas se dieron procesos represivos que estuvieron en sintonía con las teorías y lineamientos de la Doctrina de Seguridad Nacional (DSN), la cual fundó gran parte de sus preceptos en la Doctrina de la Guerra Revolucionaria (DGR) emanada de la Escuela francesa: "Todos atravesados por la misma lógica que veía (o construía) en el interior de su propio territorio al enemigo a eliminar, ligado indefectiblemente al comunismo y/o a la izquierda marxista y revolucionaria” (2016: 83).

Efectivamente, Daniel Mazzei (2002) demostró que, entre 1957 y 1962, el Ejército argentino incorporó y volvió dominante la DGR, desarrollada por el Ejército francés a la luz de su experiencia en las guerras de coloniales de Indochina (19461954) y Argelia (1954-1962). ${ }^{6}$ Tomando una organización territorial basada en el cuadriculado o compartimentación del terreno similar al que las tropas francesas aplicaron en Argelia, el país fue dividido en áreas, zonas y subzonas, a partir de la necesidad de conquistar y defender la población y otorgando un rol central a la guerra psicológica (Mazzei, 2002: 129 y 131). Si bien en 1962 se produjo el fin de la influencia directa francesa y empezó a aumentar la norteamericana -con la Alianza para el Progreso y el masivo envío de militares a las escuelas de capacitación de los Estados Unidos y el Canal de Panamá-, Mazzei planteó que fue la influencia francesa la que puso las bases teóricas, metodológicas e incluso semánticas que guiaron el accionar represivo durante la década de 1970, así como para la elaboración e internalización de la DSN:

La población, en su totalidad, se transforma en sospechosa, en enemigo potencial, prefigurándose así el concepto de 'enemigo interno' que se extenderá luego a toda la actividad opositora. (...) en toda guerra revolucionaria, el enemigo se oculta y se mimetiza en medio de la población con el apoyo de la misma. Por ello, en la lucha contrarrevolucionaria, el problema clave reside en la forma de obtener información (renseignement) para conocer la estructura organizativa del enemigo. Según quienes elaboraron esta doctrina, los interrogatorios son el principal instrumento

época, centralmente la lectura sistemática del diario tucumano La Gaceta (adelante LG) entre 1975 y 1977 y materiales de campo de mi tesis doctoral sobre la experiencia de los soldados conscriptos enviados al Operativo Independencia.

6 Ello fue así no solo gracias a la instalación en Buenos Aires de una misión militar francesa, sino también a partir del envío de militares argentinos a cursos en Francia. 
para obtener información y debe recurrirse a cualquier método para obtenerla, incluyendo la tortura de los simples sospechosos. De esta forma, la tortura fue aceptada como una práctica habitual y cotidiana por los militares franceses y las tropas en Argelia. No obstante, sus responsables no siempre utilizaron esa palabra, sino que recurrieron a eufemismos tales como 'métodos de acción clandestina y contrarrevolucionaria' (Mazzei, 2002: 125).

En esta misma línea, en un trabajo pionero Samuel Amaral planteó que: "La influencia francesa se advierte en la definición general del fenómeno revolucionario, mientras que la norteamericana aparece al considerar su expresión en América -la guerra de guerrillas- y las medidas de defensa continental" (1998: 193). La doctrina norteamericana permitió al Ejército argentino situarse en un esquema de seguridad continental, sumándole elementos fácticos en el nivel geopolíticos y dándole un lugar en el concierto de naciones anticomunistas (Ranaletti, 2009: 278; Slatman, 2010: 436 y 437). El Ejército argentino llegó al golpe de Estado de 1976 "habiendo consolidado una doctrina militar propia que, si bien pudo haberse originado por el impacto de las doctrinas militares francesa y norteamericana en desarrollo durante ese período, en sus resultados fue producto de internalizaciones, reformulaciones y prácticas propias sobre terreno" (Slatman, 2010: 432). En función de este desarrollo doctrinario, Mario Ranaletti demostró "las FF.AA. no contemplaban otra posibilidad que el aniquilamiento del enemigo 'subversivo"' (2009: 278).

En esta línea de trabajos, el presente artículo buscar aportar una mirada distinta, en tanto desarrolla un estudio de caso en profundidad (una campaña militar) sobre el que contamos con muchas más fuentes que sobre el resto de las experiencias represivas desarrolladas en Argentina (Garaño, 2012). Coincido con aquellos autores que plantean que la doctrina de "guerra antisubversiva" en Argentina excedió ampliamente los modelos francés y norteamericano, dando así lugar a una amalgama original (García, 1995; Vezzetti, 2002; Ranalletti, 2009; Slatman, 2010). Lejos de ser una aplicación lineal o exportación de dichas doctrinas extranjeras al escenario argentino, en este artículo planteo la hipótesis de que el ejercicio directo de la represión en el Operativo Independencia le permitió al Ejército tanto dotar de una impronta nacional a la doctrina represiva, así como entrenar a la tropa en esta modalidad represiva en la "zona de operaciones" de Tucumán, donde el Ejército puso en práctica por primera vez las nuevas técnicas contrainsurgentes. A su vez, sostendré que esto fue posible gracias a un sistema de rotación de personal que implicó el envío a Tucumán de amplios sectores del personal militar en actividad.

En este trabajo mostraré que, a la par del decreto presidencial que dio inicio a la campaña militar de 1975 y de la doctrina militar antes reseñada, el Operativo Independencia fue regulado por una serie de directivas y órdenes militares secretas. El objetivo de este trabajo no será contrastar las normas con las prácticas castrenses; tampoco tener una mera mirada normativa sobre las FFAA. Considero que estas directivas militares son parte del material a analizar, así como un insumo que permite acceder a la lógica de ese universo represivo. Sostendré que el valor de este tipo de documentos militares radica en que guiaron la praxis 
represiva que alentaba el Ejército en relación a sus integrantes: las directivas y órdenes secretas operaron como un 'deber ser' o un potente imperativo sobre el ejercicio de la represión, que orientaron las prácticas castrenses. ${ }^{7}$

\section{El inicio del Operativo Independencia: la fase de aislamiento y control poblacional}

Luego de las avanzadas represivas realizadas durante 1974, el 9 de febrero de 1975 las autoridades militares desplegaron un vasto operativo represivo con el fin explícito de destruir a la Compañía de Monte "Ramón Rosa Jiménez”, un frente de guerrilla rural creado un año antes por el Partido Revolucionario de los Trabajadores-Ejército Revolucionario del Pueblo (PRT-ERP), una de las principales organizaciones político-militares de izquierda que operaba desde 1970 en Argentina (ver Carnovale, 2011, entre otros). Además de este objetivo explícito, también se buscó disciplinar una zona de fuerte conflictividad sindical y política, sobre todo, a partir del cierre de once ingenios azucareros entre 1966 y 1967 (Pucci, 2007).

Esta acción militar representó la delimitación de una "zona de operaciones" en la llamada "lucha contra la subversión", que abarcó tanto la zona sur de la provincia como la ciudad capital, San Miguel de Tucumán. A esto se sumó la movilización de miles de soldados, oficiales y suboficiales de todo el país y la subordinación al comando operacional del Ejército del resto de las fuerzas de seguridad. En esta primera etapa, el frente de las operaciones militares estuvo el general Adel Vilas, comandante de la V Brigada de infantería del Ejército argentino, con asiento en Tucumán y, luego de diciembre de 1975 y durante dos años, Antonio Domingo Bussi. El puesto de comando táctico de avanzada se ubicó en la ciudad de Famaillá.

El 5 de febrero, la presidenta constitucional María Estela Martínez de Perón había ordenado, a través de un decreto, que el "Comando General del Ejército procederá a ejecutar las operaciones militares que sean necesarias a efectos de neutralizar y/o aniquilar el accionar de elementos subversivos que actúan en la provincia de Tucumán". ${ }^{8}$ Sin embargo, el Operativo fue regulado por una serie de directivas y órdenes militares secretas, normas de baja jerarquía que brindaron al Ejército una amplia cuota de discrecionalidad y autonomía en el ejercicio de la violencia estatal. ${ }^{9}$

El 23 de enero de 1975, el comandante general del Ejército, teniente general Leandro Anaya, había emitido la directiva $N^{\circ} 333$, que definió las principales características de esta acción militar. Según esta directiva secreta, en la zona sudoeste de Tucumán

7 Para este enfoque sobre las FF.AA., me inspiré en el trabajo de Eilbaum y Sirimarco sobre justicia y policías (2004).

8 Decreto del Poder Ejecutivo Nacional (PEN) nro. 261, fechado el 5/2/1975. Fue desclasificado y publicado en: Boletín Oficial de la República Argentina, 9/04/2013, p. 5.

9 Archivo personal de Antonius Robben, Utrecht, Estado Mayor del Ejército argentino, “Evaluación del Operativo Independencia”, 1978: p. 15 (En adelante, “Eval. OI, 1978”). 
"el oponente" había creado un "frente rural", con un total de entre 300 a 350 hombres, que contaba con "elementos extranjeros y con una estructura celular de apoyo", tanto en la zona como en la ciudad (Dir.333/75, pp. 2 y 3). Con una duración prevista de seis meses, a partir del día "D” (el 9 de febrero de 1975) el comando III Cuerpo de Ejército debía llevar adelante las "operaciones de seguridad y eventualmente ofensivas" contra las "fuerzas irregulares" que operaban tanto en la zona rural como en el ámbito urbano de toda la provincia, "ocupando y permaneciendo en la zona, con la finalidad de eliminar a la guerrilla y recuperar el pleno control por parte de las fuerzas del orden” (Dir. 333/75, p. 4). El control de la población se complementaría con "la organización, instrucción, acostumbramiento y el conocimiento del terreno por la propia fuerza, para acrecentar progresivamente la presión sobre la guerrilla hasta su total eliminación” (Dir. 333/75, p. 4). ${ }^{10}$

Inicialmente la campaña militar constaba de dos fases. Con la finalidad de "debilitar al oponente", privarlo de "recursos y de apoyos" y de tornarle "inestable" la zona, la primera fase consistía en desplegar las unidades en la zona rural, al oeste de la ruta nacional 38, para provocar el aislamiento de la Compañía de Monte. La finalidad era obstruirle "el espacio geográfico y político, con el objeto de impedir bajar del monte y, si lo hacía, esperarlo con emboscadas al pie del mismo” (Eval. OI, 1978: p. 26). Además, la primera fase suponía:

- la ocupación de "puntos críticos (poblaciones que apoyan a la guerrilla y/o principales lugares de escape)";

- el ejercicio progresivo del control sobre la población, rutas internas (mediante la constitución de patrullas fijas), límites provinciales (Salta, Catamarca y Santiago del Estero) y establecimientos industriales, a cargo de las fuerzas policiales;

- la progresiva intensificación del "patrullaje ofensivo" y el accionar contra la guerrilla urbana en toda la provincia, lo que permitiría obtener "experiencia sobre las exigencias de la operación a desarrollar";

- y los desplazamientos a nuevas bases de combate, "en lugares presumiblemente ocupados por el oponente". ${ }^{11}$

En línea con la DSN, se sumaba la ejecución paralela de un programa de acción cívica que buscaría solucionar los problemas sociales que aquejaban a la población (Eval. OI, 1978: p. 20; Vilas, 1977: 33-35).

Planificada para desarrollarse entre junio de 1975 y marzo 1976, la segunda fase, llamada de "hostigamiento progresivo", buscaría debilitar al "oponente", restarle "seguridad", obligarlo a mostrarse para "eventualmente atacarlo para aniquilarlo" y restablecer el "pleno control” de la zona. Además, suponía las siguientes acciones:

- "Explotación de la acción de inteligencia", "lograda a través del apoyo que la población proporcionará una vez que se sienta respaldada por la presencia del Ejército";

10 Archivo de la Cámara Federal de Apelaciones de la ciudad de Buenos Aires (en adelante, CFA), "Causa 13 ", Comando General del Ejército argentino, directiva 333/75, "Para las operaciones contra la subversión en Tucumán", p. 2 y 3 (En adelante, "Dir. 333/75").

11 Dir. 333/75, pp. 4 y 5; Eval. Ol, 1978: p. 20. 


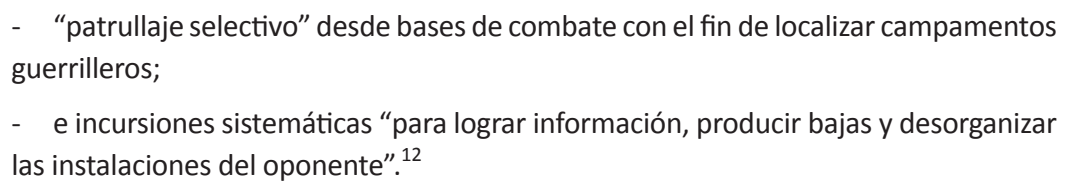

Siempre según datos oficiales y solo para dar un panorama de la fuerte ocupación militar que supuso esta campaña, en la fase de "aislamiento" se habrían destinado 2.500 hombres, constituidos por cuatro regimientos de infantería, “elementos” de comando y de apoyo (comunicaciones, helicópteros, apoyo logístico), 250 hombres de Gendarmería Nacional, 200 de Policía Federal argentina y 800 de la Policía de la provincia de Tucumán (Eval. OI, 1978: pp. 21 y 22).

Inicialmente, participaron de las operaciones militares todas las unidades de la V Brigada de infantería del Ejército, cuyos efectivos eran renovados cada 45 días, y fueron organizados en tres fuerzas de tareas (FT), distribuidos a lo largo del territorio del sur de la provincia de Tucumán. Conformada en base a dos equipos de combate y un total de 260 hombres, cada FT tenía una jefatura y una plana mayor, un escalón de comunicaciones y uno logístico, y personal de inteligencia: ${ }^{13}$

» la FT "Aconquija”, ubicada en el casco del ex ingenio Santa Lucía, estaba compuesta por una jefatura y plana mayor del Regimiento de infantería (RI) 19, con asiento en Tucumán, y dos equipos de combate, compuestos por: una compañía del RI 19 y otra del Regimiento de infantería de Monte (RIM) 28, con asiento en Tartagal, Salta.

" la FT "Chañi”, cuya base de operaciones funcionaba en la escuela de la localidad de Los Sosa, cuya jefatura y plana mayor correspondían al Regimiento de infantería de montaña (RIM) 20; estaba integrada por dos equipos de combates, una compañía del RIM 20 y una batería del Grupo de artillería de montaña (GAM) 5, ambos con asiento en Jujuy. Luego de la muerte de un oficial con ese nombre en el Operativo Independencia, el 14 de febrero de 1975, pasó a llamarse FT “capitán Cáceres”, ubicada en la localidad de Monteros.

» la FT "Rayo", que ocupó el ingenio La Fronterita cercano a Famaillá, cuya jefatura y plana mayor pertenecían al Destacamento de explosivos de la compañía militar 141; e integrada por dos equipos de combates, uno perteneciente a la compañía de escuadrón de dicho Destacamento y el otro a la Brigada de ingenieros de combate 141, ambos con asiento en Santiago del Estero.

El dispositivo represivo se completaba con la presencia del escuadrón de Gendarmería Nacional "San Juan", compuesto por 150 hombres, enviado hacia la zona de El Mollar y La Angostura (Vilas, 1977: 2-5; Eval. OI, 1978: 21). Quince días después del inicio de las operaciones, el comando del III Cuerpo de Ejército decidió la puesta en funcionamiento de la cuarta FT, denominada "Cóndor”. Según las

12 Dir. 333/75, p. 5; Eval. OI, 1978: p. 20.

13 FAMUS, 1988: 17, 157 y 196; González Breard, 1999: 186. 
memorias de Vilas, fue ubicada "a caballo de la quebrada de Lules, para cubrir el espacio que hay entre San Pablo y Lules, llegando hasta Villa Nougués y Potreros de las Tablas"; su jefatura y plana mayor correspondía al RIM 16 y contaba con dos equipos de combate compuestos por una compañía de ese regimiento -con asiento en Uspallata, Mendoza- y otra del RIM 22 -con asiento en San Juan (Vilas, 1977: Segunda Parte: 18). Por último, el comandante del III Cuerpo de Ejército, Luciano Benjamín Menéndez, ordenó la entrada en operaciones de un segundo escuadrón de Gendarmería Nacional, "Jesús María”, "para cerrar el espacio entre San Javier y Villa Nougués al norte” (Vilas, 1977, Segunda Parte: p. 18). ${ }^{14}$

Mapa 1

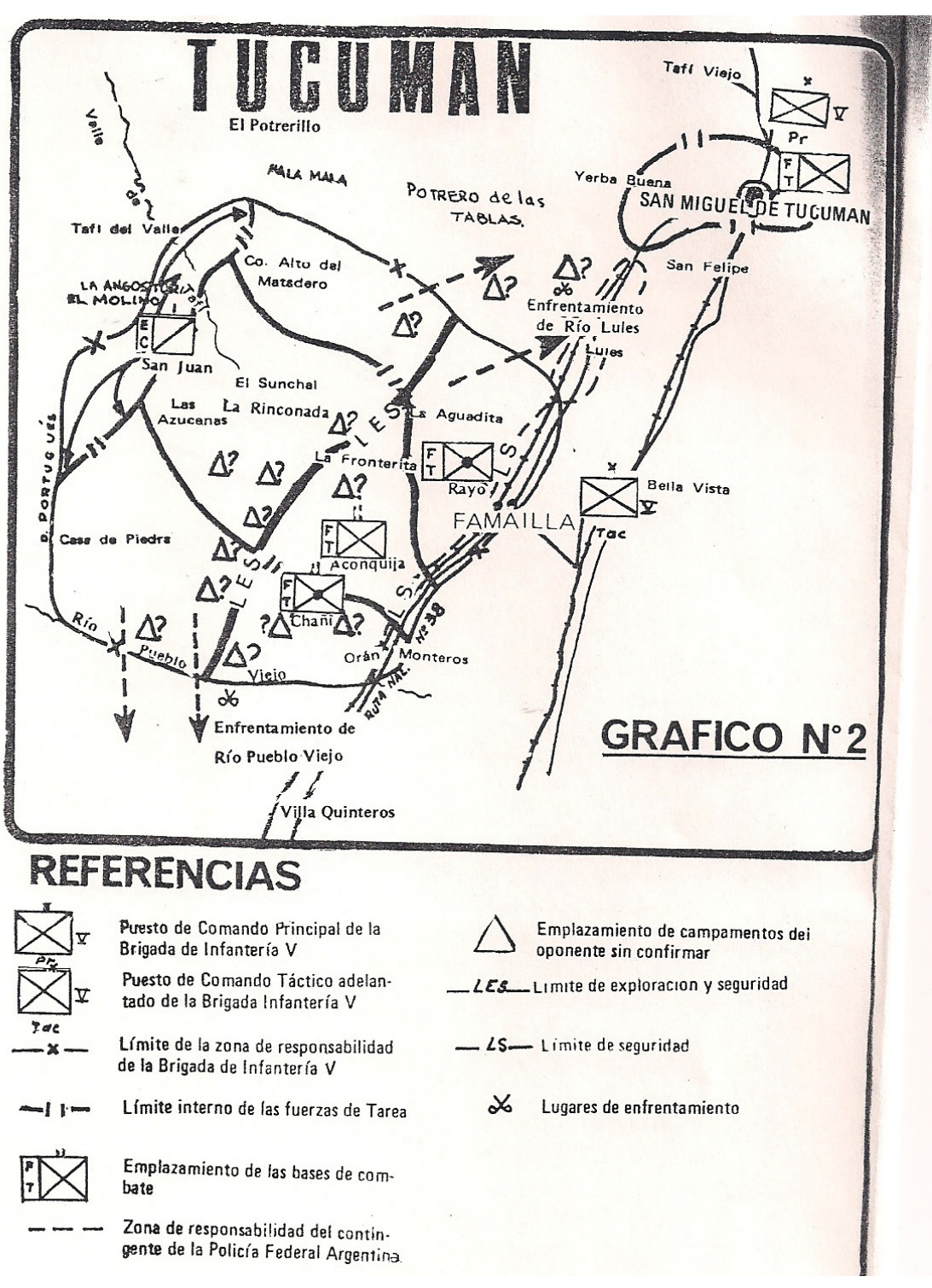

Emplazamiento de las fuerzas y grupos de tareas en la provincia de Tucumán a inicios del Operativo Independencia. Fuente: Vilas, 1977: p. 6.

14 El plan táctico nro. 6 (del 1 de octubre hasta el 20 de diciembre) modificó parcialmente este dispositivo. Ver: Vilas (1977: plan táctico 6, p. 1); y González Breard (1999: 221 y 221). 
Pero, ¿qué función tenían dichas fuerzas de tareas? ¿Se trataba de lo que luego se conocerá como "grupos de tareas"? Por un lado, durante esa primera etapa, se abocaron a desarrollar tareas de control poblacional (Simeoni, 1985:46, 136, 153). Según recordó Vilas, se emprendió un relevamiento del enclave urbano y un censo de los 12.000 habitantes: "Cualquier cambio de domicilio o viaje que se efectuara fuera del poblado debía reportarse a los efectivos del Puesto de Comando; toda arma que se tuviese, incluidas las de caza, debían ser denunciadas y entregadas; toda información que los famaillenses conocieran acerca de la subversión debían reportarla” (1977: Parte tercera, p. 1). También, un oficial destinado a Los Sosa, recordó que la primera tarea que les había tocado había sido "reunir información" sobre la población, lo que les permitió saber "quién era el que habitaba cada casa" (Simeoni, 1985: 38). Sin embargo, rememoró que, especialmente, controlaban los almacenes, para contrarrestar la estrategia de "abastecimiento hormiga de los guerrilleros" y que les tomó tiempo persuadir a los almaceneros de que no sólo no les vendieran mercadería a supuestos guerrilleros, sino que, además, hicieran la denuncia ante las autoridades militares (1985: 38).

Por otro lado, sobre la política de detención de personas, Vilas detalló su decisión de prescindir de la justicia ("no sin declarar una guerra a muerte a abogados y jueces complacientes o cómplices de la subversión”), así como la clasificación de los detenidos en tres grupos, según su importancia y peligrosidad, "de modo tal que los más peligrosos e importantes nunca llegaran a la cárcel 'General Urquiza”' y sólo lo hicieran los “inofensivos” (1977: Tercera Parte, pp. 25 y 26).

\begin{abstract}
Las Fuerzas de Tarea dependientes de la [V] Brigada [de Infantería] tenían 24 horas para tomarle declaración a los detenidos, tras lo cual debían remitirlos a Famaillá, donde esperaban los interrogadores del Ejército que yo, en forma personal, los había elegido. En el Lugar de Reunión de Detenidos se procedía a separarlos en grupos. Algunos recuperaban su libertad por falta de méritos; otros, a los cuales se les había comprobado que tenían explosivos y armas de guerra pasaban -siempre y cuando no los necesitásemos para seguir interrogándolos- a la Justicia Federal de Tucumán; un tercer grupo iba a la cárcel General Urquiza a disposición del PEN [Poder Ejecutivo Nacional] (1977: Tercera Parte, p. 10).
\end{abstract}

Aun sin explicitar que uno de estos tres grupos era una potencial víctima de la desaparición forzada de personas, a primera vista este tipo de procedimiento contradecía el anexo I de la directiva 333, donde se detallaban las "Normas de procedimiento legal". En ellas se disponían que, en el desarrollo de las operaciones militares, "los elementos sospechosos o incursos en hechos subversivos o conexos" serían detenidos y puestos a disposición del Poder Ejecutivo Nacional (PEN) y, en caso de que se hubiera reunido "elementos probatorios suficientes", debían ser sometidos a la justicia. ${ }^{15}$ Sin embargo, un análisis más sutil revela que, de hecho,

15 Se distinguían aquellas detenciones que podían ser practicadas por personal militar en el transcurso de acciones ofensivas (tales como patrullaje ofensivo y selectivo, incursiones sistemáticas y ataques) y, por el otro, las que se desarrollaban en otras operaciones (como ocupación de puntos críticos y control de población), que deberían ser practicadas "preferentemente" por personal policial (p. 1). Para la "generalidad de los casos", las fuerzas policiales debían contar "con suficiente antelación" con las órdenes de allanamiento, mientras que todo requerimiento hacia los jueces debía ser elevado al Comando general del Ejército (Dir. 333, Anexo I, p. 3). Luego de su detención, los aprehendidos debían ser remitidos a la autoridad policial provincial o federal, "para su identificación, alojamiento y suministro de información", 
se le brindaba una amplia cuota de discrecionalidad en el ejercicio del poder militar. Por ejemplo, se habilitaba la realización de allanamientos "en la medida en que las necesidades lo exijan" y en virtud de la suspensión de las garantías constitucionales por la vigencia del estado de sitio -declarado en noviembre de 1974. Según este anexo, "su ejecución no requiere de manera indispensable la previa autorización judicial”, de la que "podrá prescindirse cuando razones de urgencia o de circunstancias obliguen a obrar sin dilación” (Anexo I, Dir. 333/75, p. 2). Entonces, si bien superficialmente parecía contradictoria con la decisión militar de privilegiar el secuestro, el cautiverio ilegal y (eventual) la desaparición forzada de personas (antes que la prisión a disposición del PEN y/o por orden judicial, dispuesta en la directiva 333/75), una segunda lectura nos muestra que fue esta norma secreta la que habilitó la potestad del personal militar de realizar allanamientos y detener sospechosos, dotando de un gran poder al personal militar destinado a la "zona de operaciones" de Tucumán.

En esa misma línea, Vilas destacó que "el foco de la infección marxista" estaba en San Miguel de Tucumán: "porque de las declaraciones tomadas en [el Lugar de Reunión de Detenidos que funcionaba en] Famaillá llegamos a la conclusión de que la base de operaciones del ERP era la ciudad y no el monte como suponían algunos. Sin la cobertura que les daba Tucumán, los campamentos situados en plena selva no hubiesen resistido treinta días de lucha" (1977: Tercera Parte, p. 10; ver también González Breard, 1999: 261). Así, las FT desplegadas en el sur de la provincia eran "secundadas" por las tropas que operaban en la ciudad, donde se encontraba el "verdadero meollo del problema", por lo que las autoridades militares determinaron que los grupos operativos desarrollaran su accionar centralmente en el ámbito de la ciudad capital de Tucumán (Vilas, 1977, Tercera Parte, p. 3; Eval. OI, 1978: p. 26). Para evitar "provocar el vacío" en la zona de operaciones, ${ }^{16}$ el plan táctico tenía previsto el emplazamiento de dos "grupos de tareas" urbanos:

"En la capital de la provincia, la FT "San Miguel" estaba integrada un total de 290 hombres: una compañía del RI 19, una sección de la compañía comando y servicio de la V Brigada, una de la Compañía de arsenales 5 y una sección de la Compañía de comunicaciones 5; junto con 60 hombres de la guardia de infantería de la Policía Federal argentina y treinta de un "grupo especial" de la Policía de la provincia de Tucumán.

y "en el plazo más breve posible, que no deberá exceder las 48 horas", el comandante de la V Brigada debía solicitar a la Jefatura III (Operaciones) del Comando general del Ejército la detención a disposición del PEN "de las personas cuyos antecedentes sumarialmente recogidos y evaluados así lo justifiquen". En: Dir. 333/75, Anexo I, p. 2.

16 En función de las experiencias represivas previas, Vilas cambió la estrategia militar: "se insistía en sostener que el meollo del problema estaba en el monte y que, consecuentemente, adoptando los medios necesarios para la lucha contra la guerrilla en la selva, el brote subversivo sería aniquilado. Siguiendo esta concepción, el general de brigada Luciano Benjamín Menéndez se introdujo en dos oportunidades -agosto y noviembre del 74- en la selva sin encontrar a un solo irregular (...). Es que éstos, convenientemente avisados desde la ciudad capital, habían abandonado la zona, haciendo caer a las fuerzas del Ejército en un vacío" (Vilas, 1977: 15 y 16). 
» En la ciudad de Concepción, se organizó un "grupo especial” de treinta hombres de la Policía de la provincia de Tucumán. ${ }^{17}$

Según el documento "Evaluación del Operativo Independencia", estos "grupos de tareas" estaban constituidas por personal militar seleccionado especialmente, que contaba con instrucción de "comando", lo que les otorgaba "una gran aptitud combativa, por la destreza y alto grado de solvencia en el manejo de armas, explosivos y otros medios" (1978: 26). Desde la perspectiva de este informe oficial, durante el período inicial del Operativo, el personal militar que contaba con la llamada Aptitud Especial de Comando tuvo "el peso de la lucha", con la orientación de los integrantes de los servicios de inteligencia: "fueron los que buscaron, enfrentaron y aniquilaron a los DT(s) [Delincuentes Terroristas] de la Ca. M. [Compañía de Monte] Ramón Rosa Jiménez, en un elevado porcentaje” (1978: 26 y 27; ver también Fraga, 1988: 134). ${ }^{18}$

Como se puede observar en el material analizado, el Operativo Independencia representó una verdadera ocupación territorial del sur tucumano, basada en la fuerte presencia castrense y una serie de FT distribuidas en la zona sur de Tucumán, comandadas por autoridades militares, pero con apoyo de otras fuerzas de seguridad (policías federales y de la provincia e integrantes de Gendarmería Nacional). ${ }^{19}$ Por su parte, Vilas reconoció la existencia de un Lugar de Reunión de Detenidos (LRD), conocido como "La Escuelita" de Famaillá, donde eran llevados los prisioneros y sometidos a interrogatorios a cargo de personal militar de inteligencia especialmente seleccionado por las autoridades castrenses, que decidía su destino final. Como consideraban que el centro del "accionar subversivo" era la ciudad y no el sur tucumano, en las dos principales ciudades de la provincia operaban dos "grupos de tareas" urbanos, conformados con personal de inteligencia y con Aptitud Especial de Comando.

El jefe de inteligencia, González Breard, consideró que la "naturaleza del oponente" (un "enemigo difuso, solapado y alejado de las leyes de la guerra") los había obligado a "adoptar procedimientos inéditos en la guerra afrontada: entre otros, debió imponerse el más estricto secreto sobre la información relacionada con las acciones militares y sus logros, las operaciones en desarrollo y las comprobaciones realizadas" (1999: 260 y 251). Sobre el rol que jugaba esta nueva modalidad represiva, Vilas detalló que: "si la lucha en la que estábamos empeñados dependía de la inteligencia, el Lugar de Reunión de Detenidos sería clave para el desenvolvimiento del 'Operativo Independencia”' (1977: 10). En ese marco, el primer comandante del operativo recordó que:

17 Eval. OI, 1978: p. 26; Vilas (1977: 42 y 43).

18 Ver también Simeoni (1985: 34 y 35).

19 Además de las distintas unidades y armas del Ejército, también participó la Armada, enviando grupos de observadores activos que rotaban cada 30/40 día. Burzaco (1994: 139); (22 de noviembre de 1975), La Gaceta, Tucumán. A partir de la directiva "Benjamín Matienzo" del 31 de marzo de 1975, la Fuerza Aérea tomó a su cargo la custodia del aeropuerto de la ciudad de Tucumán; y, luego de la directiva “Cooperación”, se dispuso que esa fuerza asistiera a la V Brigada de infantería en tareas de inteligencia. En: Archivo CFA, Buenos Aires, "Causa 13", Fuerza Aérea argentina, directivas "Benjamín Matienzo", del 31 de marzo de 1975, y “Cooperación”, del 25 de abril de 1975. Ver también: Fraga (1988: 241); Burzaco (1994: 141); y Vilas (1977: PT nro. 6, p. 16). 
Hubo que olvidar por un instante -un instante que se prolongó diez meses- las enseñanzas del Colegio Militar y las leyes de la guerra donde el honor y la ética son partes esenciales, aunque muchos no lo crean así, consubstanciarse con este nuevo tipo de lucha para extraer saldos positivos. Si por respeto a las normas clásicas nos hubiésemos abstenido de emplear métodos no convencionales, la tarea de inteligencia -y ésta era una guerra de inteligencia- se habría tornado imposible de llevar adelante (1977, Tercera Parte: 6 y 7).

Sin dudas, se seguían los lineamientos de la doctrina contrainsurgente francesa y la de Seguridad Nacional, de origen norteamericano: "El campo de batalla es la población y el elemento clave es la información. Es necesario ganar a aquella y obtener ésta para destruir a la organización armada clandestina del enemigo (Amaral, 1998: 182). En función de esta doctrina, en Tucumán operó una epistemología de la sospecha, basado en la noción de que el enemigo estaba infiltrado y solapado en la población civil. Por lo tanto, quienes vivían en el sur tucumano fueron convertidos en (potenciales) colaboradores de la guerrilla y, para conjurar esa amenaza, se expandió el poder militar y se habilitó el desarrollo de fuertes tareas de control poblacional. También, se permitió la detención ilegal de personas -sin control judicial ni del Poder Ejecutivo nacional-, su confinamiento en centros clandestinos, la obtención de información mediante tortura y la eventual desaparición forzada de sus cuerpos (en caso de ser asesinados).

\section{Un nuevo sistema de relevos: rotación y participación militar}

A un mes del inicio del operativo, se modificó el esquema de envío de las tropas, que en un principio había incluido solamente a las guarniciones de la V Brigada de infantería del Ejército. El 28 de febrero el comandante general del Ejército, teniente general Leandro Anaya, emitió la orden de personal $N^{\circ} 591$, que dispuso una nueva modalidad de reclutamiento del personal militar que iba a ser enviado a la "zona de operaciones", a partir del 9 de marzo de $1975 .{ }^{20}$ Por un lado, esta medida se tomó debido a que el efectivo de personal de cuadros estaba por debajo de lo requerido; y, por otro, para que en el Operativo Independencia estuvieran representadas la mayor cantidad posible de unidades del Ejército y que el "máximo posible de oficiales y suboficiales del cuerpo comando adquieran experiencia de combate sobre este tipo de operaciones" (OP 591/75, p. 1). Ese refuerzo se iba a realizar en tres agrupamientos de unos 68 oficiales y suboficiales, que iban a permanecer 32 días en la zona de operaciones, siendo distribuidos en las distintas FT. Con esta misma tónica, el 20 de marzo de 1975, el comando general del Ejército emitió la orden de personal n ${ }^{\circ}$ 593, que dispuso relevos en tandas de 29 oficiales y suboficiales, por lapsos de 55 días aproximadamente. De esta manera, se debía "aprovechar experiencia de combate del personal relevado en los elementos de origen y proporcionarle la oportunidad de obtenerla”. ${ }^{21}$ Siempre según datos

20 Archivo CFA, Buenos Aires, "Causa 13", Comando General del Ejército, orden de personal nro. 591 ("Refuerzo a la V Brigada de infantería"), 28 de febrero de 1975, p. 1 (En adelante, OP 591/75).

21 Archivo CFA, Buenos Aires, "Causa 13", Comando General del Ejército, orden de Personal nro. 593 (“Relevo"), 20 de marzo de 1975, p. 1 (En adelante, OP 593/75). Ver también Vilas, 1977: Plan Táctico 2, 
oficiales y sólo para dar una dimensión de la cantidad de personal castrense involucrado en esta acción militar, el informe oficial asegura que, a partir de este nuevo sistema de rotación del personal militar, los efectivos se incrementaron a siete regimientos de infantería, contabilizando un total de 4.800 hombres (Eval. OI, 1978: p. 22).

Vilas aseguró que había tenido veinticuatro días para realizar una "acelerada pero exhaustiva instrucción de cuadros y tropa”, que fue completada con una "serie de charlas sobre la naturaleza y fin de la empresa marxista" así como sobre "los rigores que se avecinaban y la forma de enfrentarlos" (1977: 45). Sin embargo, como el "cambio de mentalidad" requería de la colaboración de hombres ya entrenados, estimó de "inapreciable valor" la llegada, una semana antes del operativo, de un contingente de la Policía Federal "acostumbrada a estas lides pues sobre ella recaía la responsabilidad de la lucha antisubversiva en el país. Junto al mismo y un haz seleccionado de oficiales, comenzamos a entrenarnos todos los días" (1977: 45).

Según documentos militares, se necesitaron cuatro meses para "adaptarse a la vida y combate en el monte" (Eval. OI, 1978: pp. 26-7). Como no existían experiencias previas sobre este tipo de lucha no convencional, el jefe de inteligencia González Breard sostuvo que se fue pasando de "la improvisación a un paulatino aprendizaje de la realidad de un enemigo distinto que empleaba una metodología diferente" (1999:249-250,280).14 En términos similares, Vilas recordó que a medida que el tiempo transcurría, la experiencia en el ejercicio de la represión iba creciendo:

De esta manera, los grupos especiales salían a operar día y noche, procediendo a ejecutar o capturar al oponente. De inmediato, en el Lugar de Reunión de Detenidos se les tomaba declaración y de acuerdo a la misma, estaba preparado otro grupo para proceder a investigar los datos que nos daba el subversivo interrogado. En realidad, nuestro trabajo resultaba similar a una cadena que no podía tener ningún tipo de trabas burocráticas. Comprendiendo esto, impartí órdenes de que, en la ciudad de Tucumán, los grupos encargados de las misiones especiales estuviesen trabajando, sin interferencias, las 24 horas del día. (...) Si el procedimiento de detención se había realizado vistiendo uniformes del Ejército, entonces no había más remedio que entregarlo a la justicia para que a las pocas horas saliese en libertad; pero si la operación se realizaba con oficiales vestidos de civil y en coches 'operativos', como lo ordené ni bien me di cuenta de lo que era la 'justicia' y la partidocracia, la cosa cambiaba (Vilas, 1977: Tercera Parte, p. 8-10).

Además de reforzar con cuadros las unidades de la V Brigada (cuya tropa estaba integrada por soldados conscriptos) y dar a la mayor cantidad posible de oficiales y suboficiales experiencia de combate directo contra la guerrilla, Fraga sostuvo que "se buscaba comprometer a todos los cuadros para evitar que se constituyera una suerte de elite de combatientes que en el futuro creara situaciones difíciles a la cohesión de la fuerza”, tal como le explicaron dos generales destinados por entontes al Estado Mayor (1988: 134 y 171). 
Como podemos observar en el material analizado hasta aquí, el Operativo Independencia parece haber tenido una doble misión. Además de imponer un dominio militar en la conflictiva provincia de Tucumán -no sólo en el sur de la misma- y lograr la destrucción del "oponente", esta acción militar buscaba que el personal militar acumulara experiencia represiva. Así, gracias al nuevo sistema de rotación del personal militar arriba detallado -que implicaba la participación de amplios sectores del Ejército en las operaciones desarrolladas en esa provincia-, Tucumán se volvió un espacio de entrenamiento y aprendizaje en términos de adopción de nuevas formas de represión. ${ }^{22}$ Consideramos que la masiva movilización de personal militar fue una vía para iniciarse en el ejercicio de una nueva modalidad represiva que se ensayaba por primera vez en la zona de operaciones de Tucumán. Quizás fue propicio que se tratara de un espacio relativamente alejado de los grandes centros urbanos, tal como reconoció el jefe de inteligencia de esta campaña: "tanto por la lejanía del teatro de operaciones como también por otros factores, la lucha en los montes tucumanos no afectaba la vida diaria argentina que se trasuntaba en una indiferencia de la ciudadanía sobre lo que estaba sucediendo" (González Breard, 1999: 15).

\section{La intensificación de las operaciones y la llegada de Bussi}

Con fecha del 18 de septiembre de 1975, en las instrucciones nro. 334 se hizo una evaluación de la marcha de la campaña militar. Luego de seis meses de operaciones, las autoridades militares consideraban necesario continuar las operaciones en Tucumán, hasta que se lograran dos circunstancias: por un lado, los "efectos de una acción nacional integrada, aspecto que está en vías de ser encarado a través del planeamiento correspondiente"; y por el otro, una "ampliación del éxito militar logrado localmente para reducir la subversión en la zona a niveles aceptables". ${ }^{23}$

En este documento militar se consideraba que el "oponente" todavía mantenía "su estructura de combate y apoyo en condiciones de operar, pese a los éxitos obtenidos por la propia fuerza” (Instrucc. 334/75, p. 3; subrayado en el original). Gracias al despliegue de las fuerzas militares en la zona y las acciones "exitosas" que habían ejecutado, el primer resultado del Ejército fue interrumpir el proceso de formación de un frente rural, mientras que el segundo, obtener "cierto grado de control sobre la población, sin llegar al que sería de desear” (Instrucc. 334/75, p. 10 y 11). Se destacaba que "los resultados cuantitativos con respecto al daño producido a la estructura subversiva en Tucumán” eran "importantes y muy positivos", gracias a "la libertad de acción que se ha dispuesto para establecer y mantener un dispositivo adecuado, en despliegue e intensidad, y para ejecutar operaciones sin restricciones" (Instrucc. 334/75, p. 12). ${ }^{24}$

22 Véase: Fraga (1988: 239).

23 Archivo CFA, Buenos Aires, "Causa 13", Comando General del Ejército, instrucciones nro. 334 (“Continuación de las operaciones en Tucumán"), 18 de septiembre de 1975, p. 2 (En adelante, "Instrucc. $334 / 75 ")$.

24 El tercer resultado había sido "neutralizar la guerrilla, dificultando sus vínculos con la población” y, el 
En función de esta evaluación, a partir del $1^{\circ}$ de octubre de 1975 , se daba cuenta de que el comando del III Cuerpo de Ejército "intensificará las operaciones" en la provincia de Tucumán, especialmente en la zona sur (p. 15). Para ello, consideraban necesario "diseñar dispositivos flexibles y ágiles que, independientemente de los efectivos de las Fuerzas de Tareas, consideren la disposición de una reserva del comando de operaciones con vistas a complementar las acciones que lleven a cabo las unidades" (p. 17). Se planteó la posibilidad de subdividir la zona de acción en sentido longitudinal, de norte a sur, diferenciando las operaciones que se desarrollarían en el llano de la zona montañosa. Todo ello permitiría modificar el despliegue como la organización para el combate, "independizar los comandos" y que las incursiones adquirieran paulatinamente mayor permanencia (Instrucc. 334/75, pp. 17 y 20).

Esta medida fue paralela al decreto 2772/75, de octubre de 1975, mediante el cual el Poder Ejecutivo nacional extendió la función represiva contrainsurgente del Ejército de Tucumán a todo el territorio argentino. ${ }^{25}$ En ella, se mantuvo como una "zona estratégica prioritaria” el eje Tucumán, Salta y Jujuy y se determinó que las operaciones militares en Tucumán se debían continuar con la orientación dictada por las instrucciones 334/75.

Unos meses más tarde, el 15 de diciembre, se nombró al por entonces general de brigada Bussi ${ }^{26}$ como reemplazante de Vilas, quien dejó el cargo el 21 de ese mes. ${ }^{27}$ Según el relato de Vilas, si bien el Operativo Independencia no había finalizado, era "un éxito completo": "La subversión armada había sido total y completamente derrotada por un Ejército que luego de cien años de paz demostraba su capacidad de combate. La mayor satisfacción fue recibir días después, ya estando en la Capital Federal, el llamado del general Bussi, quien me dijo: 'Vilas, Ud. no me ha dejado nada por hacer'” (1977: PT Nro. 6, p. 19). ${ }^{28}$ Un poco

cuarto, "reducir la capacidad operacional del aparato para-militar subversivo y su estructura de apoyo" (pp. 11 y 12). En aras de aislar a la guerrilla de todo apoyo exterior, consideraban necesario cerrar las vías terrestres de comunicación que unían a Tucumán con los otros "centros subversivos que proporcionan refuerzos" (Instrucc. 334/75: p. 16 y 18).

25 La primera fase consistía en "accionar en todo el territorio nacional, en forma simultánea e integral", con la finalidad de "reducir significativamente el accionar subversivo". Archivo CFA, Buenos Aires, "Causa 13", Decreto 2772/75 de octubre de 1975 del PEN. Directiva del Consejo de Defensa 1/75, p. 2. Sobre este tema, ver también Pontoriero (2014).

26 Egresado de la promoción 76 del Colegio Militar de la Nación como oficial de infantería en 1947, en diciembre de 1974 había sido nombrado general de brigada. A mediados de 1963, se trasladó a la Escuela Superior de Guerra del Fuerte Leavenworth, donde se egresó como oficial del Estado Mayor del Ejército de los Estados Unidos de América (2011: 65-68).

27 Además, se designó como nuevo jefe del Regimiento 19 de infantería al teniente coronel Ernesto Alais y al mayor Miguel Alfredo Paz como su segundo, y al nuevo 2을 comandante y jefe del Estado mayor de la V brigada, coronel Antonio Llamas, reemplazando al coronel Alberto Luis Cattáneo (17 de diciembre de 1975, 29 de diciembre de 1975; y 22 de diciembre de 1976, La Gaceta, Tucumán, tapa). Por su parte, el 9 de septiembre había asumido Mario Benjamín Menéndez como jefe del estado mayor del operativo militar (10 de septiembre de 1975), La Gaceta, Tucumán.

28 Vilas (1977: PT Nro. 6, pp. 16 y 17). Vilas consideró fundamental el llamado "combate" que se desarrolló el 10 de octubre en la zona del arroyo San Gabriel, al norte de Acheral, en el que se habían combinados dos hechos: "el puramente militar, que costó al ERP 12 de sus hombres más fogueados, y el psicológico, pues, a semejanza de Manchalá, en un combate abierto había sido totalmente derrotado. (...) Desarticulado en la ciudad, barrido de su periferia industrial, cercado en los cañaverales, perseguido en el monte, sin abastecimientos, sin suministros, sin capacidad ninguna de reclutamiento, el ERP estaba derrotado" (1977: PT N 6, p. 5; ver también, Fraga, 1988: 242). En el resumen de la actividad de la V Brigada de infantería durante 1975, se detallan: 37 combates, 58 campamentos, instalaciones y depósitos 
menos contundente fue Bussi, quien -quizás para cargar las responsabilidades sobre Vilas- recordó que, durante la comandancia de Vilas se había desarrollado "la parte más cruenta, en términos de bajas y de combate", y sobre la táctica militar afirmó que:

Reconozco que la etapa que llevó a cabo Vilas, que se centraba en dirimir por las armas quién dominaba la situación, se hizo eficazmente. (...) La táctica que siguió fue inteligente. Evitó entrar al monte, para no enfrentar a las tropas contra los guerrilleros en situación desfavorable, ante el dominio que ejercían desde las colinas montuosas, donde estaban establecidos desde hacía mucho tiempo. A su vez, con la presencia militar, logró que los subversivos quedaran aislados de la población, cortándose parcialmente la posibilidad de abastecerse. Ya no podían subir y bajar de los montes hacia las ciudades (...) sin riesgo, dado que la presencia de las tropas del Ejército era importante en toda la zona de operaciones (Bussi, 2011: 131-132).

Bussi cuestionó que la conducción de Vilas había sido "un tanto anárquica, dado que había grupos que operaban cada uno por su cuenta” y que -por ejemplo- las Policías Federal y de la provincia no respondían a su comando (2011: 132). En función de esta apreciación, Bussi dispuso que la conducción debía estar "bien centralizada" y restringió el accionar represivo a cuadros del Ejército, destacando el retiro de la Policía Federal argentina y el repliegue de la Policía provincial a operaciones de seguridad en centros urbanos y de los efectivos de Gendarmería nacional, a la custodia de "objetivos específicos” (¿los llamados Lugares de Reunión de Detenidos o LRD?) (2011: 138). ${ }^{29}$ Así, Bussi enfatizó que participó “directamente en la conducción de mis hombres en el monte” y que los más de 10 mil efectivos respondían a su mando (2011: 138 y 170).

Según la memoria de Bussi, durante su comandancia la presencia militar no se restringió al sudoeste, sino a toda la provincia de Tucumán, ya que se propuso "desmantelar todo el aparato subversivo" que tenía una "estructura muy importante en las ciudades" (2011: 145). Recordó que, durante la primera etapa de su comandancia, lo animaba especialmente la "conquista, la ocupación territorial del monte tucumano" (2011: 138). En ese marco, a partir de enero de 1976, desarrolló una serie de operativos, el primero de los cuales se denominó "Lamadrid I", que consistió en desplegar efectivos sobre el terreno y realizar una "avanzada todo a lo largo del monte, de este a oeste, desde la

destruidos, 18 emboscadas con resultados positivos, 160 bajas enemigas, 53 bajas propias (González Breard, 1999: 18 y 228). De todas maneras, González Breard reconoció que, con excepción de lo sucedido en Manchalá el 28 de mayo de 1975 y en el arroyo San Gabriel, no hubieron "grandes combates con enfrentamientos de fuerzas importantes", sino que la mayoría fueron "combates de encuentro y emboscadas"; a su vez, como las "operaciones diurnas" habían dejado un "saldo negativo", se debieron realizar "actividades nocturnas, descansar de día" (1999: 262).

29 Según su relato, desmanteló la "célebre" "Escuelita” de Famaillá, "que ya había dado mucho que hablar": "Por haberse constituido en un 'lugar de retención masiva', donde se alojaba no solo a prisioneros de guerra sino también a sospechosos que a la postre, no tenían nada que ver. Quería reducir al máximo la posibilidad de ocasionar disgusto en la población, por las arbitrariedades que se cometen en todo tipo de conflicto armado. Suplí ese lugar para la detención e interrogatorio de los detenidos por el clásico régimen policial, dado que las dependencias de policía estaban preparadas para dicho cometido" (Bussi, 2011: 138). Sin embargo, desde 1983 en adelante, se ha documentado que durante su comandancia se inauguró un nuevo LRD en el predio de la Compañía de arsenales "Miguel de Azcuénaga”, con características de un verdadero centro clandestino de tortura, encierro y exterminio, oculto en pleno monte, camino a la localidad de Tafí Viejo (ver CONADEP, 1984). 
llanura hasta el Aconquija", un rastrillaje completo del monte en el que se produjeron numerosos "enfrentamientos” (Bussi, 2011: 138 y 139). Según recordó un ex soldado conscripto de la clase militar 1954:

\begin{abstract}
Cuando asumió Bussi, (...) él cambio la táctica, (...) porque tenían informes de que la guerrilla estaba prácticamente derrotada, que había que dar el golpe final. Entonces, por primera vez, cambió la táctica y ya no eran excursiones esporádicas, sino que fuimos todos a rastrear el monte. Ésa fue toda una operación, una movilización muy grande, el 1ro. de enero, y por eso es que nos habían traído a todos a Monteros, abandonamos los puestos que teníamos cerca del monte. Nos concentramos en Monteros, otra gente se concentró en Famaillá y ahí se avanzó hacia el monte haciendo un rastrillaje. Nosotros después nos enteramos, que cuando nosotros subíamos, la guerrilla bajaba... Así que no encontramos nada. (...) Deben haber sido 15, 20 días.... ${ }^{30}$
\end{abstract}

Además de las operaciones complementarias de seguridad en distintas localidades y ciudades de la provincia, González Breard recordó que esta operación, desarrollada entre el 19 y 25 de enero, consistió en establecer una línea de emboscadas que, paralelamente a la ruta nacional nro. 38, permitiera cerrar las probables vías de acceso desde la sierra montuosa al llano: "Simultáneamente, la masa de los elementos de las FFTT [Fuerzas de Tareas] ejecutaría un rastrillaje de larga duración en la zona marginal de la sierra, con centro de gravedad en el sur de la provincia" (1999: 233). ${ }^{31}$ De esta manera, se llevaba a cabo la fase de "hostigamiento progresivo", basada en intensificar las acciones militares con el fin de destruir al "oponente".

\title{
La fase de "consolidación"
}

El 24 de marzo de 1976, las Fuerzas Armadas derrocaron el gobierno constitucional de Isabel Martínez de Perón, iniciaron el autodenominado "Proceso de Reorganización Nacional” y nombraron a Bussi como gobernador de facto de la provincia de Tucumán, quien tuvo esa función hasta diciembre de $1977 .^{32}$ Así se dio inicio a la tercera fase, llamada de "consolidación", que se extendió desde marzo de 1976 hasta la finalización de la campaña militar. Según consta en el informe "Evaluación del Operativo Independencia", si bien esta última fase no había figurado en la planificación inicial, se llevó a cabo debido a que "militarmente faltaba consolidar la victoria" (Eval. OI, 1978: p. 17). Para ello, se emprendieron las siguientes acciones militares, "en busca del aniquilamiento definitivo en la Z.O. [zona de operaciones] de los DDTT [delincuentes terroristas] guerrilleros":

30 Entrevista realizada por el autor en la ciudad de San Miguel de Tucumán, el 19 de septiembre de 2009.

31 "Entre 1976 y mayo de 1977 se llevaron a cabo numerosos operativos sobre poblaciones y rutas (...) desde la Operación Lamadrid I, II y III, hasta la Operación Interzafra, ejecutándose más de 20 acciones de importancia consistente en cercos, rastrillajes, allanamientos fiscalizaciones generales y selectivas que dieron resultados satisfactorios" (1999: 242). Sobre el concepto de esta operación, véase también González Breard (1999: 233-235).

32 A fines de 1977, designaron como interventor de la provincia al general (retirado) Lino Montiel Forzano. 
a) Continuar con las operaciones militares tendientes a la ubicación, detección, desgaste, hostigamiento y destrucción de los restos de las BDT(s) [Bandas de Delincuentes Terroristas] actuantes que aún operan en la zona.

b) Proseguir mediante un intenso esfuerzo para propender el mejoramiento de las condiciones de la población.

c) Conquistar definitivamente la población mediante la AC [Acción Cívica] y AS [Acción Sicológica] para hacerla inmune a la prédica subversiva (Eval. OI, 1978: p. 16).

En este marco podemos inscribir las instrucciones nro.335, emitidas el 5 de abril de 1976 por el jefe del Estado Mayor general del Ejército, Roberto Viola. Se planteaba que Tucumán continuaba "siendo un objetivo particular de interés para el proceso subversivo que trata de desarrollar el oponente en el ámbito nacional”. ${ }^{3}$ Se destacaba que la eficacia de la estrategia del Operativo Independencia había rendido "sus frutos": además de "un adecuado grado de control sobre la población y una relativa y parcial captación, adhesión y apoyo", se había logrado el "desgaste progresivo del oponente, privándolo de su infraestructura, aislándolo de la población, causándole importantes bajas, y haciéndolo en definitiva retroceder en el proceso de desarrollo revolucionario" (Inst. 335/76, p. 1).

En estas instrucciones, se planteaba la necesidad de continuar las "operaciones destinadas a la detección, desgaste, hostigamiento y aniquilamiento del oponente que aun opera en la Zona de Acción y la OPM [Organización Político Militar] que lo apoya, con la finalidad de reducir la subversión a niveles aceptables para transferir oportunamente la responsabilidad de otras fuerzas" (Instrucc. 335/76, p. 8). Si bien se debía tender a una transición gradual de responsabilidades hacia la Policía de la provincia de Tucumán, se consideraba necesario la presencia de las cuatro Fuerzas de Tareas en la zona, por un período "bastante prolongado", con el fin de "consolidar logros ya alcanzados y avanzar hacia la solución total y definitiva del problema": "Una mayor reducción de efectivos resultaría demasiado drástica además de contraponerse a la experiencia acumulada durante las operaciones" (Instrucc. 335/76, p. 14 y 15). En lo que se refería a la acumulación de experiencia represiva, se había incrementado "la capacidad y eficiencia de combate de propias fuerzas" y se enfatizaba que "el conocimiento logrado del terreno y ambientación conseguida, sumados a la idoneidad, espíritu de sacrificio y valor personal, aseguran una alta capacidad operacional” (pp. 1 y 5).

Asimismo, a partir del golpe de Estado, se evidencia un cambio en la estrategia represiva, siempre en aras de ganar flexibilidad en el ejercicio de la violencia, así como impedir "la reocupación de la zona de sierra montuosa por el oponente” (Instrucc. 335/76, p. 12). Destacaban la existencia de un núcleo importante de cuadros militares que contaban con Aptitud Especial de Comando (AEC) que había permitido la organización de "fracciones de relativa magnitud", que podían operar en forma semi-independiente como "caza-guerrilleros" "con lo cual es factible economizar fuerzas y obtener idénticos o mejores resultados"

33 Archivo CFA, Buenos Aires, "causa 13", Estado Mayor General del Ejército, instrucciones nro. 335 ("Continuación de las operaciones en Tucumán"), 5 de abril de 1976, p. 4 (En adelante, "Instrucc. $335 / 76$ "). 
(Instrucc. 335/76, p. 5). En esta línea, a partir del 30 de abril y hasta el 5 de septiembre de 1976 a los refuerzos previstos en las órdenes de personal nros. 591 y 593/75, se le sumaba la constitución de los equipos de cuadros militares con Aptitud Especial de Comando, cuyos relevos se debían realizar cada 60 días. Su misión era realizar operaciones comando que no excedieran los 20 días "preferentemente en la zona de sierra montuosa, para detectar y aniquilar fracciones del oponente" (Instrucc. 335/76, p. 1). ${ }^{34}$ Así, vemos que el sur tucumano continuó siendo un espacio no sólo de ejercicio de la represión sino también de entrenamiento y aprendizaje de técnicas contrainsurgentes por parte de quienes contaban con aptitudes de comando. Éstos últimos, junto al personal de inteligencia, fueron los que tuvieron un rol central en el desarrollo de las estrategias contrainsurgentes.

Combinando acción cívica y psicológica, también se propuso la elaboración de un plan estructurado a nivel provincial, con el fin de brindar "soluciones a los grandes problemas socio-económicos de la zona” (Inst. 335/76, pp. 8-10). De esta manera, la acción militar debía ser "complementada en sus logros, a fin de alcanzar la completa adhesión y apoyo de la población” y "mejorar la imagen de la Fuerza”; todo ello redundaría en "mejores resultados de la acción contra el oponente" y daría "características permanentes al éxito alcanzado" (Inst. 335/76, p. 1).

Quizás esta directiva se vincula directamente con la impronta que le dio Bussi a su gestión de gobierno. En su libro de memorias, Bussi detalló que en 1969 había sido seleccionado para integrar el segundo contingente de militares argentinos destinados como observadores militares a Vietnam, donde conoció "el verdadero horror de la guerra, en su faz brutal y descarnada" (2011: 90). Además, aseguró que había comprendido que "para ganar la guerra no solo se necesita tener superioridad militar, absoluto dominio del espacio aéreo, tropas bien entrenadas, sino también tener a la población de aliada y creer firmemente en los ideales por los que se lucha” (2011: 92). En función de ello, Bussi recordó que el eje central era ganarse el apoyo de la población (el fin último de la guerra de guerrillas) y para ello era necesario "eliminar las causas del accionar subversivos", dar respuesta a las "injusticias sociales que eran el caldo de cultivo de la subversión desatada" (2011: 133, 134 y 136).

\section{A modo de cierre}

En la orden especial N ${ }^{\circ} 336$ del 25 de octubre de 1976, rubricada por el jefe del Estado mayor general del Ejército, Roberto Viola, se dispuso continuar las operaciones militares, pero disminuir los efectivos empeñados. Como se consideraba que la presencia militar en la zona había logrado resultados “excelentes”, se tomó la decisión de reestructurar el dispositivo y dar máxima prioridad a la acción

34 Se preveía la designación de tres oficiales con AEC (un jefe y dos oficiales instructores), pertenecientes a Escuela de infantería, cuya responsabilidad sería el adiestramiento en la zona de Tucumán de patrullas compuestas por doce cuadros (Inst. 335/76, p. 4). 
de gobierno -“apoyada y explotada por la acción psicológica”-, especialmente, a partir del desarrollo de "planes de desarrollo comunitario" en la zona rural y la instalación de bases de combate semi-permanentes. ${ }^{35}$

Como se puede observar, una vez producida la derrota de la "subversión” en Tucumán, para las autoridades militares era momento para iniciar un repliegue militar. De todas maneras, esto debía ir acompañado de una presencia permanente y de dejar una huella en el territorio tucumano, a partir de la creación de estos cuatro pueblos, donde se reagrupó a los pobladores dispersos del pedemonte y se ejerció una férrea vigilancia y un control social, político y moral sobre ellos (Nemec, 2018). La construcción de cuatro pueblos en el sur tucumano, que llevarían el nombre de militares caídos en el marco del Operativo Independencia, era una potente forma de imponer una nueva hegemonía en las relaciones sociales de esa zona de Tucumán y de escenificar la victoria sobre la llamada "subversión" (Garaño, 2015). Esto se potenció con un fuerte plan de gobierno, basado en intensificar las tareas de acción cívica y psicológica.

Vemos que el Operativo Independencia supuso una doble cara: destrucción y producción. Es decir, el ejercicio de la violencia de Estado buscaba, vía la presencia militar, disciplinar e imponer un nuevo orden en la sociedad tucumana. Se valieron de una combinación entre acción represiva, psicológica y cívica, los tres elementos de la doctrina contrainsurgente vigente en Argentina desde la década de 1960. En esta línea, fue fundamental la fuerte presencia castrense en la zona, la ocupación territorial, la presencia de FT distribuidas en puntos estratégicos y el fuerte control poblacional. También, todos los documentos analizados muestran que el Operativo Independencia se basó en la idea de que se debía librar una guerra no convencional, frente a un "combatiente irregular", cuyas principales armas eran el ocultamiento y la clandestinidad. Este tipo de modalidad represiva suponía una amplia discrecionalidad en el ejercicio de la represión social y política, la detención por sospecha, el secuestro ilegal, la posibilidad de realizar interrogatorios bajo tortura en los llamados en jerga castrense "LRD" (Lugar de Reunión de Detenidos) y la desaparición de los cuerpos de los disidentes políticos asesinados.

Para cerrar este trabajo, queremos plantear una serie de cuestiones que quedan abiertas para futuros análisis. En principio, es evidente la distancia que presentan las normas -directivas y órdenes militares- con respecto a las prácticas de los

35 Archivo CFA, Buenos Aires, "causa 13", Estado Mayor General del Ejército, orden especial nro. 336 (“Continuación de las operaciones en Tucumán”), 5 de abril de 1976, pp. 1-3 (En adelante, OE 336/76). Se dispuso continuar operando con "fuerzas equivalentes" a dos fuerzas de tareas y dos equipos de combate; por lo que, del refuerzo previsto para el 8 de noviembre, sólo se iba a requerir la mitad de los relevos. A su vez, implicaría un despliegue paulatino del personal militar "para no afectar bruscamente la capacidad de combate" y evitar "reacciones sicológicas desfavorables en la población y/o brindar oportunidades favorables al accionar del oponente" (OE 336/76, pp. 3 y 4). Este nuevo dispositivo se ajustaba a la orden parcial nro. 405 que había dispuesto una reestructuración de jurisdicciones y "adecuación orgánica para intensificar las operaciones contra la subversión" (p. 2). En este marco, se detallaba que: "La proporción mayoritaria de la agresión subversiva se materializa sobre las grandes concentraciones industriales del país, delineándose claramente cuatro regiones de mayor actividad, que son por orden de prioridad: Capital Federal y Gran Bs As, Gran La Plata, Región Ribereña del Río Paraná (desde Zárate hasta San Lorenzo) y Córdoba” (p. 1). Archivo CFA, Buenos Aires, "Causa 13", Estado Mayor General del Ejército, orden parcial nro. 405, 21 de mayo de 1976. 
actores, que nunca se ajustan a las primeras. En segundo lugar, y directamente vinculado con lo anterior, me parece fundamental reflexionar sobre las limitaciones que presentan este tipo de normas militares que poco hablan sobre la modalidad por excelencia del ejercicio del poder, a saber, la desaparición forzada de personas. En este sentido, en el corpus de fuentes analizadas para este trabajo, la única excepción es el "diario de campaña" de Vilas. En este libro, el primer comandante del Operativo Independencia publicó un listado del "bajas del oponente", reconoció la existencia de "procedimientos especiales", el empleo de tropas entrenadas para operativos irregulares, así como la existencia de detenidos alojados en los "LRD". ${ }^{36}$ En cambio, en el resto de las fuentes analizadas sólo se hallan indicios del terrorismo de Estado y prima un relato bélico, la puesta en escena de una guerra. En ellas, el Operativo Independencia es narrado como una sucesión de planes militares -detallando las "bajas" del oponente y las propias, ocurridas en ataques, "emboscadas" y "enfrentamientos"-, mientras que son escasos los relatos de detenciones y secuestros y siempre pertenecen a activistas de la Compañía de Monte del PRT-ERP, antes que a otro tipo de opositores políticos (obreros, estudiantes o dirigentes de izquierda).

Pese a las limitaciones anteriormente señaladas, hemos realizado una aproximación a la lógica y dinámica represiva del Operativo Independencia. A diferencia del grueso de los trabajos sobre doctrina militar citados en la introducción -que se centran en reglamentos y directivas aplicadas a nivel nacional-, en este trabajo reconstruí las principales características de una campaña militar específica. A partir del análisis de sus principales fases, hemos mostrado cómo el esquema represivo de esta campaña militar fue modificado en función de la acumulación de experiencia represiva y de los cambios sucedidos en contexto nacional. Y que, antes que una planificación inicial, esta campaña se fue (re)formulando a la luz de la experiencia adquirida y del propio proceso represivo.

He mapeado la presencia de las distintas Fuerzas de Tareas que operaron en la Provincia, mostrando la fuerte presencia castrense en la provincia y la lógica del esquema represivo. También he dado cuenta acerca de cómo, de modo paralelo al ejercicio de la violencia, las autoridades consideraban que el Operativo Independencia era un espacio fundamental para que el personal militar acumulara experiencia represiva en lo que refiere a las nuevas técnicas contrainsurgentes. Así, el Ejército pudo tener un campo de entrenamiento, alejado de los grandes centros urbanos y de las críticas de la opinión pública. Así se le dotó de una impronta nacional a la doctrina contrainsurgente.

En este sentido, esta investigación -basada en documentos elaborados por las mismas fuerzas intervinientes- comprueba que en el sur tucumano las autoridades militares ensayaron el terrorismo de Estado que, luego de marzo de 1976, se extendió a otros lugares del país. Ello fue así debido a la implementación de

36 Vilas aseguró que, desde el 10 de febrero hasta el 18 de diciembre de 1975, "pasaron por el Lugar de Reunión de Detenidos 1507 personas acusadas de mantener relación estrecha con el enemigo" (1977: Tercera Parte, p. 11). Además de ello, publicó un "listado de enfrentamientos", con un total de 226 asesinados. 
un aceitado sistema de rotación de personal jerárquico y de la tropa del Ejército, pero también de otras Fuerzas Armadas y de seguridad, tales como las Policías Federal y provincial y Gendarmería nacional. De todas maneras, si bien se buscó comprometer a toda la institución castrense, el rol central lo cumplió personal adiestrado especialmente para este tipo de modalidad represiva, que contaban con Aptitud Especial de Comando y de inteligencia, tanto al inicio del Operativo como la fase final donde se conformaron fracciones de grupos de "caza-guerrilleros". 


\section{Q Bibliografía}

\section{Fuentes citadas}

"Decreto secreto del PEN nro. 261, firmado el 5/2/1975. Fue desclasificado y publicado en: Boletín Oficial de la República Argentina, 9/04/2013, p. 5.

\section{Archivo de la Cámara Federal de Apelaciones en lo Criminal y Correccional de la ciudad de Buenos Aires (CFA), "causa 13":}

" Directiva de comandante general del Ejército nro. 333 ("Para las operaciones contra la subversión en Tucumán"), 23 de enero de 1975.

" Plan de Acción Sicológica 1/75 (“Apoyo problema Independencia”), 5 de febrero de 1975.

" Orden de personal nro. 591 ("Refuerzo a la V Brigada de infantería"), 28 de febrero de 1975.

"Orden de personal nro. 593 (“Relevo"), 20 de marzo de 1975.

" Instrucciones nro. 334 (“Continuación de las operaciones en Tucumán”), 18 de septiembre de 1975.

"Directiva del Consejo de Defensa nro. 1 ("Lucha contra la subversión"), 15 de octubre de 1975.

" Directiva de comandante general del Ejército nro. 404 ("Lucha contra la subversión"), 28 de octubre de 1975.

" Instrucciones nro. 335 ("Continuación de las operaciones en Tucumán"), 5 de abril de 1976.

"Orden parcial nro. 405/76, 21 de mayo de 1976.

" Orden especial nro. 335 ("Continuación de la Operación Independencia”), 25 de octubre de 1976.

" Directivas "Benjamín Matienzo 75", del 31 de marzo de 1975, y "Cooperación”, del 21 de abril de 1975 (Fuerza Aérea Argentina).

\section{Archivo personal de Antonius Robben, Utrecht, Países Bajos:}

" Estado Mayor del Ejército (1978). “Evaluación de la Operación Independencia”.

\section{Bibliografía}

" Almada, V. (coord) (2015). Operativo Independencia. Avance e Inteligencia - Operativo Independencia. En: Segado, S. (coord.); Relevamiento y análisis documental de los Archivos de las Fuerzas Armadas (1976-1983). Buenos Aires: Ministerio de Defensa, pp. 213-274.

" Amaral, S. (1998). Guerra revolucionaria: de Argelia a la Argentina, 1957-1962. Investigaciones y ensayos, 48, pp. 173-195. 
" Basualdo, V. (org.) (2015). Ingenio Concepción e Ingenio La Fronterita. En: AA.VV.; Informe Responsabilidad empresarial en delitos de lesa humanidad: represión a trabajadores durante el terrorismo de Estado. Buenos Aires: Ministerio de Justicia y Derechos Humanos de la Nación. Pp. 35-111.

" Burzaco, R. (1994). Infierno en el monte tucumano. Argentina 1973-1976). Buenos Aires: RE Editores.

" Bussi, J. L. (2011). Mi padre, el General. Biografía de Antonio Domingo Bussi. San Miguel de Tucumán: edición del autor.

" Calveiro, P. (1998). Poder y desaparición. Buenos Aires: Colihue.

" Carnovale, V. (2011). Los combatientes. Buenos Aires: Siglo XXI.

"Círculo Militar (1976). El Ejército de hoy (Páginas para su historia). Homenaje del Círculo Militar a los camaradas caídos en la Lucha contra la Subversión. Buenos Aires: Círculo Militar.

"Colombo, P. (2017). Espacios de desaparición. Vivir e imaginar los lugares de la violencia estatal (Tucumán, 1975-1983). Buenos Aires: Miño y Dávila.

"Comisión Bicameral investigadora de las violaciones a los derechos humanos en la provincia de Tucumán (1991). Informe de la Comisión Bicameral investigadora de las violaciones a los derechos humanos en la provincia de Tucumán. San Miguel de Tucumán: Universidad Nacional de Tucumán.

" CONADEP (1985). Nunca más. Informe de la Comisión Nacional sobre la desaparición de personas. Buenos Aires: EUDEBA.

" Crenzel, E. (2010). El Operativo Independencia en Tucumán. En: Orquera, F. (ed.); Ese ardiente Jardín de la República. Formación y desarticulación de un "campo" cultural: Tucumán, 1880-1975. Córdoba: Alción Editora. Pp. 377-400.

"Duhalde, E. L. (1999). El Estado terrorista argentino. Quince años después. Buenos Aires: EUDEBA.

"Eilbaum, L. y M. Sirimarco (2004). Una discusión sobre los procesos de investigación etnográfica en el campo judicial y policial. En: Wilde, G. y P. Schamber (comp.); Culturas, comunidades y procesos urbanos contemporáneos. Buenos Aires: Ediciones SB.

" FAMUS (1988). Operación Independencia. Buenos Aires: FAMUS.

" Fraga, R. (1988). Ejército: del escarnio al poder (1973-1976). Buenos Aires: Planeta.

" Franco, M. (2012). Un enemigo para la Nación. Orden interno, violencia y "subversión", 1973-1976. Buenos Aires: Fondo de Cultura Económica.

" Garaño, S. (2012). Entre el cuartel y el monte. Soldados, militantes y militares durante el Operativo Independencia (Tucumán, 1975-1977). Tesis de doctorado, Facultad de Filosofía y Letras, Universidad de Buenos Aires.

" Garaño, S. (2015). La construcción de los cuatro pueblos en el pedemonte tucumano. La apuesta productiva del Operativo Independencia (Tucumán, 1975-1977). Avances del Cesor, 12, pp. 157-170.

" García, P. (1995). El drama de la autonomía militar. Argentina bajo las Juntas Militares. Madrid: Alianza Editorial.

" González Breard, E. (1999). La guerrilla en Tucumán. Una historia no escrita. Buenos Aires: Círculo Militar.

" Jemio, A. (2013). Lineamientos teórico-metodológicos para el estudio de la estrategia represiva del Ejército durante el Operativo Independencia. Lules, Famaillá y Monteros, 
Tucumán. 1975-1976. Ponencia presentada en las X Jornadas de Sociología, Universidad de Buenos Aires.

" Mazzei, D. (2002). La misión militar francesa en la Escuela Superior de Guerra y los orígenes de la Guerra Sucia, 1957-1962. Revista de Ciencias Sociales, 13, pp.105-137.

" Nemec, D. (2018). Pueblos de la "guerra". Pueblos de la "paz". Los pueblos rurales construidos durante el "Operativo Independencia" (Tucumán, 1976-1977). Tesis de maestría, Centro de Estudios Latinoamericanos, Universidad Nacional de San Martín.

"Périès, G. (2009). La doctrina militar contrainsurgente como fuente normativa de un poder de facto exterminador basado sobre la excepcionalidad. En: Feierstein, D. (org.); Terrorismo de estado y genocidio en América Latina. Buenos Aires: Prometeo. Pp. 221-247.

" Pontoriero, E. (2014). La seguridad interna como teatro bélico: legislación de defensa y contrainsurgencia en la Argentina (1966-1973). Ponencia presentada en el Workshop "La represión en la historia reciente argentina: modalidades locales y regionales y estudios de caso. Intercambios y debates sobre las experiencias de investigación". Rosario, Argentina.

"Pontoriero, E. (2016). De la guerra (contrainsurgente): la formación de la doctrina antisubversiva del Ejército argentino (1955-1976). En: Águila, G., S. Garaño y P. Scatizza (org.); Represión estatal y violencia paraestatal en la historia reciente argentina: nuevos abordajes a 40 años del golpe de Estado. La Plata, Editorial Facultad de Humanidades y Ciencias de la Educación, Universidad Nacional de La Plata. Pp-47-71.

" Pucci, R. (2007). Historia de la destrucción de una provincia. Tucumán 1966. Buenos Aires: Del Pago.

" Ranalletti, M. (2009). Contrainsurgencia, catolicismo intransigente y extremismo de derecha en la formación militar argentina. Influencias francesas en los orígenes del terrorismo de Estado (1955-1976). En: Feierstein, D. (org.); Terrorismo de estado y genocidio en América Latina. Buenos Aires: Prometeo. Pp. 249-281.

" Robben, A. (2008). Pegar donde más duele. Violencia política y trauma social en Argentina. Barcelona: Anthopos.

"Scatizza, P. (2016). Un Comahue violento. Dictadura, represión y juicios en la Norpatagonia argentina. Buenos Aires: Prometeo.

"Simeoni, H. (1985). Aniquilen al ERP. Buenos Aires: Ediciones Cosmos.

"Slatman, M. (2010). Una doctrina contrarrevolucionaria para el ejército argentino. Análisis de la discursividad oficial del Ejército Argentino durante la Guerra Fría (1957-1976). En: García Ferreira, R. (comp.); Guatemala y la Guerra Fría en América Latina (1947-1977). Guatemala: CEUR-USAC.

"Vezzetti, H. (2002). Pasado y presente. Guerra, dictadura y sociedad. Buenos Aires: Siglo $\mathrm{XXI}$.

"Vilas, A. (1977). Tucumán: el hecho histórico. El plan táctico que posibilitó la victoria contra el Ejército Revolucionario del Pueblo (ERP) en 1975. Mimeo. 